This is the peer reviewed version of the following article: Pascoe, A. and Breen, L. and Cocks, N. 2018. What is needed to prepare speech pathologists to work in adult palliative care? International Journal of Language \& Communication Disorders. 53 (3): pp. 542-549., which has been published in final form at http://doi.org/10.1111/1460-6984.12367. This article may be used for non-commercial purposes in accordance with Wiley Terms and Conditions for SelfArchiving at http://olabout.wiley.com/WileyCDA/Section/id-828039.html

What is needed to prepare Speech Pathologists to work in adult palliative care?

\title{
Ashleigh Pascoe
}

Profession:

Employer:

Biographical details:

\section{Dr. Lauren Breen}

Profession: Associate Professor and Psychologist

Employer:

Contact number:

Address:
Curtin University, Bentley

(08) 92667943

GPO Box U1987, PERTH WA 6845
Speech Pathologist

WA Health Department

Ashleigh Pascoe is a Speech Pathologist with a special interest in palliative care and student education.

Biographical details: Dr Lauren Breen is an Associate Professor in Psychology. Her research areas include grief and palliative care.

\section{Dr. Naomi Cocks}

Profession:

Employer:

Contact number:

Address:

Biographical details: 


\section{Declaration of Interest}

The authors report no conflicts of interest. The authors alone are responsible for the content and writing of the paper. No competing financial interests exist. 


\begin{abstract}
Background: Speech Pathologists have a pivotal role in palliative care, assisting patients with swallowing and communication disorders yet very little is known about the preparedness of Speech Pathologists to work in this field.
\end{abstract}

Aims: The current study investigated the preparedness of Speech Pathologists for working in palliative care. The term 'palliative care' was viewed as an encompassing umbrella term, incorporating the management/reduction of symptoms and improvement in a person's quality of life at any point of the disease progression.

Method \& Procedures: Participants were Australian-trained Speech Pathologists who provided adult palliative care services. An online questionnaire was used to gather both quantitative and qualitative data from practising Speech Pathologists. Qualitative data was analysed and interpreted using conventional content analysis. Descriptive statistics were analysed via the Statistical Package for the Social Sciences (SPSS) for Windows Version 22. Non-parametric tests (Chi-Square and Mann Whitney $U$ Test) were used for further analysis.

Outcomes \& Results: The majority (70\%) of participants indicated that their university training did not prepare them to practice in palliative care. Participants who received palliative care education at the tertiary level were significantly more prepared to work with palliative patients than those who had not; however, only a minority (27\%) had received such training. Just over half (57\%) reported having completed post-university professional development in palliative care. The Speech Pathologists role in palliative care was also highlighted, with Speech Pathologists outlining their contribution to the assessment of patient's communication and swallowing abilities. In addition, recommendations for palliative care content to be incorporated into university curriculum were suggested.

Conclusions \& Implications: Speech Pathologists can make important contributions to end-of-life care but there is much scope for improving the availability and quality of university and post- 
university palliative care training opportunities so that people receiving palliative care are best supported.

\section{What is already known on this subject.}

Palliative care is a complex area of Speech Pathology work. The role of the Speech Pathologist in palliative care is well documented in the literature and includes assessing and treating swallowing, communication and/or cognitive impairments. Working with patients who require palliative care can be clinically and ethically complex and Speech Pathologists would benefit from appropriate training.

\section{What this study adds.}

Speech Pathologists have not been directly surveyed as to their role in palliative care and therefore how prepared Speech Pathologists feel for practice in palliative care is not known. This paper examined Speech Pathologists' perceptions of how prepared they were for practice in palliative care, and results indicated that the majority of Speech Pathologists did not feel prepared for practice in palliative care. Preparedness was higher for those Speech Pathologists who received palliative care education as part of their university training.

\section{Clinical implications of this study.}

University training on issues such as dysphagia in relation to quality of life and risk feeding, and the opportunity to be exposed to real-life scenarios and palliative care placements, would likely increase preparedness of graduates to work in palliative care settings and would foster knowledge and potentially prevent burnout. Such education should ideally be formalised in the curriculum and complemented by post-university training opportunities. Increasing the access to, and uptake of, palliative care education would promote the value of Speech Pathologists within palliative care service delivery. 


\section{What is needed to prepare Speech Pathologists to work in adult palliative care?}

\section{Introduction}

Delivering safe, high quality palliative care services is a national priority (Australian Commission on Safety and Quality in Health Care, 2015) and is best provided by an interdisciplinary team approach (Crawford and Price, 2003, Morris and Leonard, 2007, Pollens, 2004). Speech Pathologists have a pivotal role in this team, assessing and treating swallowing, communication and/or cognitive impairments (Eckman and Roe, 2005, Frost, 2001, Pollens, 2004, Pollens, 2012, Roe and Leslie, 2010, Roe et al., 2007, Toner and Shadden, 2012). Speech Pathologists manage patients throughout the trajectory of their illness, with conditions such as cancer, Motor Neuron Disease/Amyotrophic Lateral Sclerosis, chronic obstructive pulmonary disease (COPD), Parkinson's disease and muscular dystrophy commonly found on a Speech Pathologists caseload (Eckman and Roe, 2005, Mathisen et al., 2010, Roe and Leslie, 2010, Toner and Shadden, 2012, Frost, 2001, Pollens, 2004). Within the last fifteen years, the role of the Speech Pathologist in palliative care has been more widely documented in the literature (Eckman and Roe, 2005, Frost, 2001, Hawksley et al., in press, Pollens, 2004, Pollens, 2012, Toner and Shadden, 2012, Roe et al., 2007, Roe and Leslie, 2010, Chahda et al., 2017, Kelly et al., 2016, Martins and Alves, 2017).

The Speech Pathologist's role in palliative care can be clinically complex and ethically challenging (Eckman and Roe, 2005, Frost, 2001, Pollens, 2004, Pollens, 2012, Roe and Leslie, 2010, Roe et al., 2007, Toner and Shadden, 2012) and thus adequate training is needed (Eckman and Roe, 2005, Roe and Leslie, 2010). Understanding death and the dying process from a medical and spiritual point of view (Buchanan et al., 2012, Harper, 1997, Potter et al., 1979, Toner and Shadden, 2012), as well as grieving processes (Potter et al., 1979) may assist Speech Pathologists to manage palliative patients better. Given the complexity of these issues, it has been suggested that being introduced to these concepts in a supportive environment, such as the university setting, would be valuable (Teed and Keating, 2009, Eckman and Roe, 2005, Roe and Leslie, 2010). 
Research in the medical, nursing and physiotherapy literature demonstrates the importance of embedding palliative care content into university curriculum (Kumar et al., 2011, Bush and ShahwanAkl, 2013, Anderson et al., 2008). Education at the university level results in several positive outcomes for students, such as improved competence (Bush and Shahwan-Akl, 2013), better attitudes (Anderson et al., 2008, Kumar et al., 2011), increased self-awareness and personal development (Ballesteros et al., 2014), and improved knowledge (Kumar et al., 2011, Anderson et al., 2008, Ballesteros et al., 2014) in relation to palliative care. On the contrary, it has been suggested that medical and allied health professionals who are not prepared for work in palliative care are at an increased risk of negative consequences such as stress, anxiety and burnout (Rivers et al., 2009, Truffelli et al., 2008, Meier et al., 2001). Mathisen and colleagues (2010) investigated the incorporation of palliative care units (via the Palliative Care Curriculum for Undergraduates (PCC4U) program) into their undergraduate Speech Pathology curriculum at The University of Newcastle. At the conclusion of the unit, students reported an increased understanding of palliative care, and commented that incorporating more specific Speech Pathology content would have been more beneficial.

The preparedness of Speech Pathologists for working in palliative care is not currently documented in the literature. Colleagues in Occupational Therapy have started to pave the way in this area. Meredith (2010) investigated preparedness of Australian and New Zealand Occupational Therapists for working in palliative care. In order to determine preparedness, twenty-four Occupational Therapists completed a survey with questions pertaining to university degree, palliative care university education received, preparedness for working in palliative care and current employment considerations. This study found that three quarters of studied Occupational Therapists did not feel prepared to work in palliative care; those who received education on palliative care at the university level were statistically significantly more prepared for work in this field; and those who had graduated more recently were more likely to have received palliative care education at university (Meredith, 2010). 
Given that similar research has not yet been conducted in the Speech Pathology literature, the aims of this study were to determine:

1) the role of the Speech Pathologist in palliative care

2) how prepared Speech Pathologists feel about working in palliative care

3) if Speech Pathologists who have palliative care education feel more prepared for work in palliative care

4) if having received palliative care education at university is associated with time since graduation

5) what Speech Pathologists believe universities could do to better prepare students for work in palliative care.

\section{Methods}

\section{Ethics Approval}

Ethics approval was granted from the XXXXX ${ }^{1}$ Human Research Ethics Committee (approval number: PSYCH SP 2014-28).

\section{Study Design}

This study was a cross-sectional survey of Australian-trained Speech Pathologists and their preparedness for working in palliative care. A Qualtrics online survey was used to collect both qualitative and quantitative data.

\section{Participants and Procedure}

Participants were Australian-trained Speech Pathologists who provided adult palliative care services. An information sheet containing a link to the Qualtrics survey was initially distributed to Dysphagia Interest Group (DIG) coordinators, a professional development forum for Speech Pathologists with a clinical interest in dysphagia (swallowing difficulties). It was confirmed that Speech Pathologists located in Victoria, Western Australia and New South Wales were provided with the survey link via the DIG mailing list. Queensland did not circulate the questionnaire link to their

\footnotetext{
${ }^{1}$ Name of ethics committee to be added after blind review
} 
DIG members due to their guidelines around questionnaire circulation. In order to further increase participation throughout Australia, the information sheet with the Qualtrics link was also forwarded to the Speech Pathology Email ChatS (SPECS) mailing list. SPECS is an online forum for Speech Pathologists who work with adult clients, where they are able to share and discuss knowledge, best practice and evidence. The survey was available for three months and informed consent for participation was implied upon return completed survey.

\section{Materials}

An anonymous, online questionnaire comprising 17 questions was adapted from Meredith's (2010) study of Occupational Therapists' preparedness for working in palliative care. The survey was pilot tested with two qualified Speech Pathologists prior to circulation, with feedback sought in regards to content, wording, question order, layout and survey length. Feedback received was used to remove ambiguity, ensure user friendliness and optimise relevance to the speech pathology profession. Participant demographics were measured via multiple choice and open-ended questions, whilst dichotomous choice (yes/no), ordinal scale (rank) and open-ended questions were used to measure preparedness for work in palliative care. The ordinal scale was a 5-point Likert-type scale that consisted of 'very unprepared', 'generally unprepared', 'neutral', 'generally prepared' and 'very well prepared'.

\section{Analysis}

Qualitative data obtained from the open-ended questions were analysed and interpreted using conventional content analysis (Hsieh and Shannon, 2005) rigor for the study based on quality criteria of transparency, neutrality, applicability, and credibility (Emden and Sandelowski, 1998). Numerical data were analysed via the Statistical Package for the Social Sciences (SPSS) for Windows Version 22. Analysis consisted of descriptive statistics (i.e.: mean, standard deviation and range) to describe number of palliative patients seen per week, preparedness for working in palliative care and training and professional development received in palliative care. Chi-Square was used to examine associations between time since graduation and palliative care education. A Mann-Whitney U Test 
was utilised to explore the effect of palliative care training at the university level on preparedness for working in palliative care. Significance for the study was set at $p=0.05$ and effect sizes were interpreted using Cohen's (1988) conventions (Cohen, 1988).

\section{Results}

\section{Sample Characteristics}

In total, 157 individuals commenced the survey, which yielded 143 completed responses. An overall response rate was unable to be calculated due to the unavailability of a central list of Speech Pathologists who work with adults in Australia.

Participants were employed in a variety of clinical settings (acute, outpatient, aged care, palliative care units). Respondents had studied Speech Pathology across various states and territories of Australia, with $37.8 \%$ having studied in New South Wales, $12.6 \%$ in Queensland, 6.3\% in South Australia, $16.8 \%$ in Victoria and $26.6 \%$ in Western Australia. The majority (83\%) of respondents reported they completed a Bachelor degree in Speech Pathology, and the remaining $17 \%$ had completed a Graduate Entry Masters course. Just over half (54\%) of respondents graduated within the last ten years and three quarters of the participants worked full time (Table 1).

Table 1. Participant demographics

\begin{tabular}{|l|l|}
\hline Year graduated $(n=143)$ & $1(0.7 \%)$ \\
$1972-1977$ & $3(2 \%)$ \\
$1978-1983$ & $9(6.3 \%)$ \\
$1984-1989$ & $5(3.5 \%)$ \\
$1990-1995$ & $15(10.5 \%)$ \\
$1996-2001$ & $40(28 \%)$ \\
$2002-2007$ & $70(49 \%)$ \\
$2008-2013$ & $0(0 \%)$ \\
2014 onwards & \\
\hline Employment type $(n=142)$ & \\
\hline
\end{tabular}




\begin{tabular}{|l|l|}
\hline Part-time & $35(25 \%)$ \\
Full-time & $106(75 \%)$ \\
Other (i.e.: casual, project work) & $1(1 \%)$ \\
\hline
\end{tabular}

The frequencies with which participants saw palliative care patients per week varied, with almost a third of participants seeing between two and five patients per week and $35 \%$ of respondents seeing less than one patient per week $(M=2.12, S D=0.99)$. The average number of hours spent with palliative patients varied from $1 / 2$ an hour to 38 hours per week. Variables such as the complexity of the patient/diagnosis, stage of disease progression and how well the patient had previously been managed were all factors that influenced the time documented.

Since graduating as a Speech Pathologist, 57\% of respondents reported having completed professional development in palliative care. Much of this was in the form of professional development in-services within the workplace. Some respondents commented on professional development events provided by organisations outside of the workplace (i.e., via the Cancer Council, MS Society) and self-directed learning and post graduate university courses/certificates. In terms of content, the most popular topics were advance care planning, ethics and planning at end of life.

\section{Role of the Speech Pathologist in Palliative Care}

Respondents were asked to describe their role in palliative care via open-ended questions. The Speech Pathologists described having an important and varied role within a palliative care team, with the overall goal being to maximise patient quality of life and to see "patients throughout their journey".

The role of the Speech Pathologist in palliative care was described as relating to two core practice domains - promoting communication and managing dysphagia (swallowing difficulties). Several subthemes were evident within these domains, and these are summarised in Table 2.

Table 2. Role of the Speech Pathologist in Palliative Care 


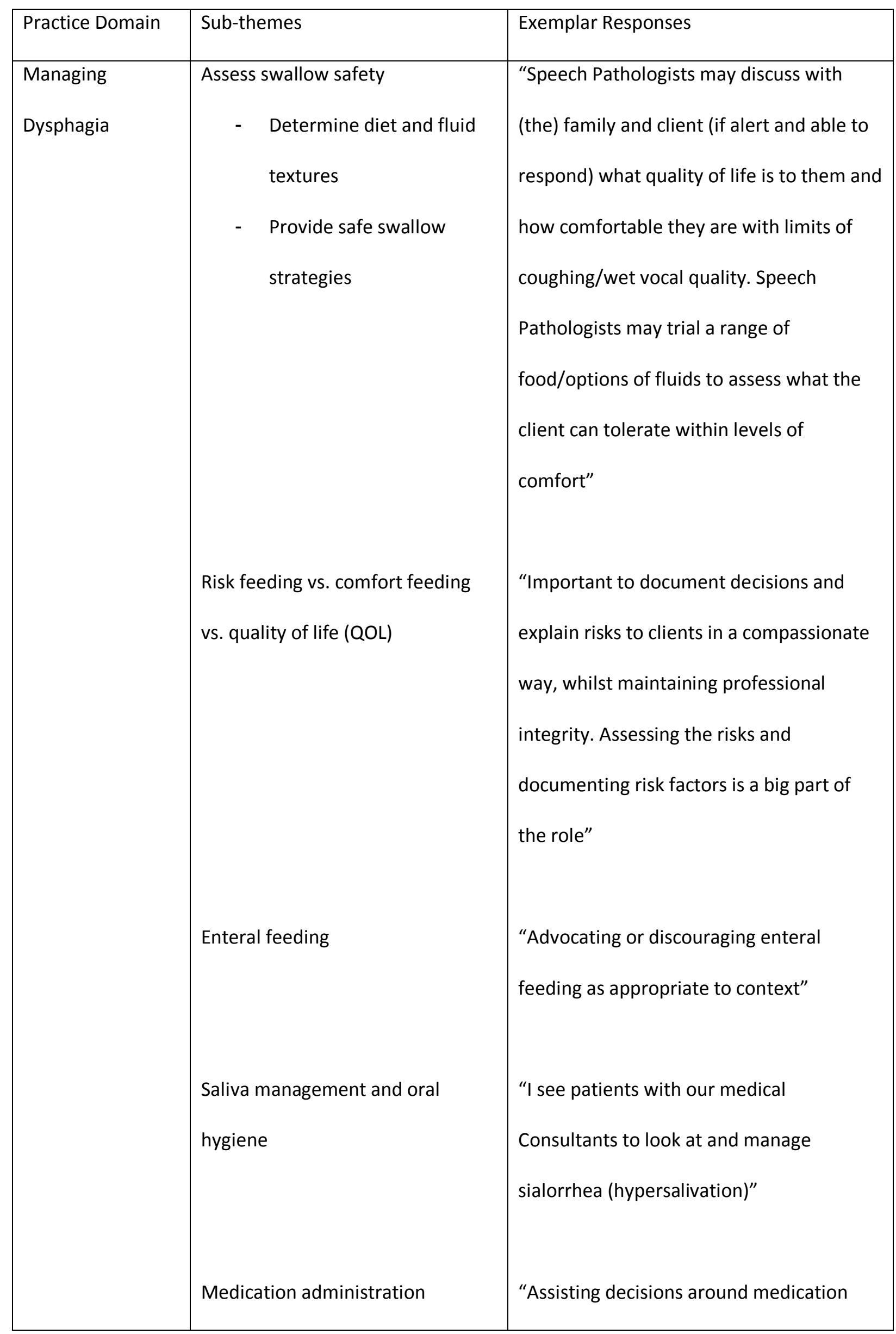




\begin{tabular}{|c|c|c|}
\hline & 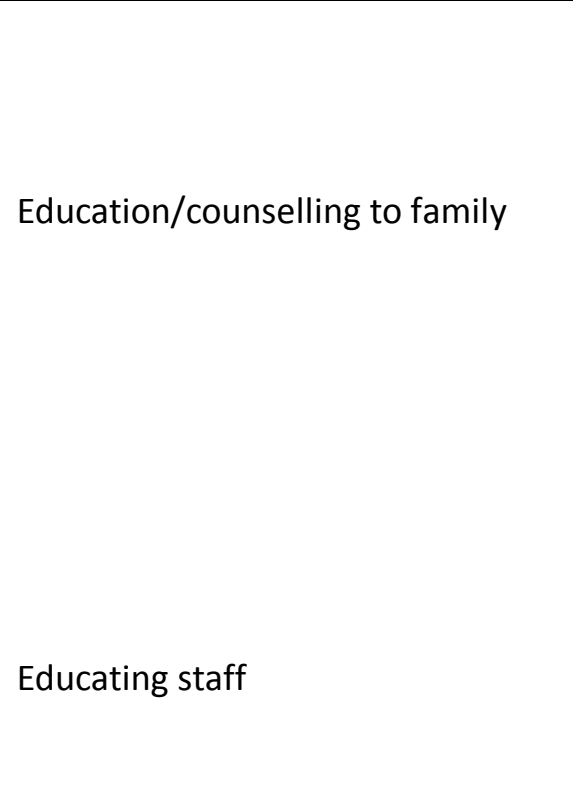 & $\begin{array}{l}\text { management" } \\
\text { "A lot of time is spent just chatting with } \\
\text { family and discussing/supporting them } \\
\text { around the changes for their family } \\
\text { member" } \\
\text { "Educating medical and nursing staff about } \\
\text { comfort feeding" }\end{array}$ \\
\hline $\begin{array}{l}\text { Promoting } \\
\text { Communication }\end{array}$ & $\begin{array}{l}\text { Assess communication skills } \\
\text { Communication strategies/support } \\
\text { for the patient or family/carer }\end{array}$ & $\begin{array}{l}\text { "I am passionate about being a visible } \\
\text { advocate for the role of the Speech } \\
\text { Pathologist in communication in aged } \\
\text { care" } \\
\text { "In addition to core Speech Pathology } \\
\text { practice, I facilitate communication } \\
\text { between patients and their families and } \\
\text { the team looking after them, especially as } \\
\text { they deteriorate and communicating } \\
\text { becomes more difficult" } \\
\text { "Putting short-term solutions in for } \\
\text { is at e.g. high level or low tech AAC, whilst } \\
\text { "Optimisation of speech-voice skills" }\end{array}$ \\
\hline
\end{tabular}




\begin{tabular}{|l|l|l|}
\hline & $\begin{array}{l}\text { knowing that flexibility in timelines and } \\
\text { thinking outside the box will assist the } \\
\text { family" }\end{array}$ \\
Cognition strategies & "Strategies to patients/families around \\
management of cognition"
\end{tabular}

While communication and dysphagia were by far the most common areas of practice, the Speech Pathologists educated and liaised with medical, nursing and allied health regarding these practice domains; educated and supported patient/family members on disease progression and the dying process; organised services/referrals for the patient to support groups, disorder specific organisations and other allied health professionals; and provided liaison regarding advance care planning and case management.

\section{Preparedness of Speech Pathologists for Working in Palliative Care}

Thirty-nine respondents (27\%) reported receiving palliative care training as part of their undergraduate/graduate entry masters Speech Pathology course. Of these 39 participants, only twenty respondents documented the elements of their course that they recalled to be related to palliative care. Most commonly, respondents reported that palliative care was mentioned to some degree in dysphagia, ethics and counselling lectures. Some (six) respondents also reported gaining palliative care experience whilst on clinical placement, this experience was mostly related to observation or discussion with a supervisor regarding care of a palliative patient. One respondent reported completing an honours project in palliative care, and another participant reported completing an elective unit in palliative care.

In reflecting on their university training, 19 Speech Pathologists (13.3\%) reported feeling very well or generally prepared for practice in palliative care, while $100(69.9 \%)$ respondents were not prepared, and $24(16.6 \%)$ were neutral in their assessment. A Mann-Whitney $U$ test indicated that 
the participants who did receive palliative care training at university reported feeling significantly more prepared for working in palliative care (Mean Rank=99.18, $n=39$ ) than those who did not receive palliative care training as a student (Mean Rank=61.81, $n=104$ ), $U=968.00, z=-5.20$ (corrected for ties), $p=<.001$, two-tailed. This effect can be described as "medium-large" ( $r=.43)$. We then examined the association between having received palliative care education and time since graduation. A Chi-Square test of contingencies was used to assess whether those who graduated more recently (since 2009) were more likely to have received palliative care education than those who graduated 2001-2008, or before the year 2000. The association was small and not significant, $\chi^{2}$ $(2, N=142)=3.408, p=.182, w=0.15$, indicating that students who had graduated more recently were not likely to have received more palliative care education than those who graduated earlier.

Respondents were asked to provide recommendations for university curricula to better prepare Speech Pathology students for palliative care. Responses are summarised in Table 3.

Table 3. University content recommendations

\begin{tabular}{|l|l|}
\hline Content & Frequency \\
\hline Basic information on palliative care i.e.: & $18(13.1 \%)$ \\
definition of palliative care; role of the Speech & \\
Pathologist in palliative care/role of other & \\
members of the team; principles/philosophy of & \\
palliative care; evidence-based practice. & \\
Ethics/legal issues, i.e.: advanced care planning; & \\
duty of care/rights and responsibilities; Enduring & $18(13.1 \%)$ \\
Power of Attorney/Guardianship (EPA/EPG); & \\
medico-legal requirements; clinical & \\
documentation requirements; case load & \\
planning.
\end{tabular}


- Counselling, i.e.: emotional engagement; self care; existential impacts; psychosocial support for patient and family; how to support families emotionally.

- Communication skills, i.e.: strategies to assist the patient communicate their wants/needs; alternative-augmentative communication (AAC) in palliative care; skills to manage complex conversations; conflict resolution skills.

- Dysphagia, i.e.: quality of life (QOL) and risk feeding; comfort care; saliva management/oral care.

- Service delivery, i.e.: when to withdraw Speech pathology input; how to plan management for a patient who is not going to get better; palliative care pathways; palliative care services that are available.

- Medical issues, i.e.: illness trajectories; clinical deterioration; information about different illnesses (e.g.: Motor Neurone Disease, Multiple Sclerosis, Parkinson's disease etc); what a dying person may experience/symptoms; impact of removal of medications; medical consequences of reduced oral intake.

- Real life learning, i.e.: practical placements in palliative care settings; role play of clinical 


\begin{tabular}{|l|l|}
\hline scenarios; clinical case studies; hearing patient & \\
stories. & \\
& $19(13.9 \%)$ \\
\hline
\end{tabular}

\section{Discussion and Implications}

This is the first study to investigate the preparedness of Speech Pathologists for working in palliative care. The Speech Pathologist's role in palliative care is well documented in the literature; however, to the best of our knowledge, this is the first time that Speech Pathologists have been surveyed about their role. This study showed that Speech Pathologists have a varied role within the palliative care team, focusing on improving patient outcomes and quality of life in relation to communication and dysphagia. However, almost three-quarters of the participants felt underprepared for working in palliative care. This result is similar to what was reported for Occupational Therapists (Meredith, 2010) and suggests a lack of preparedness for working in palliative care across both allied health professions.

Although palliative care training at university is recommended (Eckman and Roe, 2005, Roe and Leslie, 2010), only $27 \%$ of the participants reported having received palliative care training as part of their undergraduate/graduate entry masters Speech Pathology course. Importantly, there was no association with time since graduation, indicating that palliative care education is not changing significantly over time. This was not the case for Occupational Therapy, where an increase in palliative care education over time was reported (Meredith, 2010). It is not known why this difference may exist between Speech Pathology and Occupational Therapy courses, although it could be an artefact of sample size and representativeness, in that Meredith's study was of a much smaller sample. Participants who did receive palliative care training at a tertiary level were found to be significantly more prepared for working in palliative care, than those who did not receive palliative 
care training at the university level. Although this has not previously been documented in the Speech Pathology literature, this finding has been highlighted in medical and other allied health literature (Bush and Shahwan-Akl, 2013, Anderson et al., 2008, Kumar et al., 2011, Ballesteros et al., 2014). In order to improve preparedness for working in palliative care, more than half of the participants had completed professional development in this area as a qualified Speech Pathologist but there was still a considerable proportion (43\%) working in palliative care and having received no post-university palliative care professional development. Taken together, these findings are particularly concerning, given the inevitable increase in patients requiring palliative care in years to come, due to an increasing and aging, Australian population (Australian Institute of Health and Welfare, 2016).

In order to improve preparedness of graduates for palliative care, Speech Pathologists were asked to recommend content to include in university curriculum. One fifth of respondents reported that more information on dysphagia in relation to quality of life and risk feeding would be beneficial. This is potentially to do with the ethically challenging nature of this area. Real life scenarios where students had a clinical placement on a palliative care ward, had exposure to real case studies, or had guest speakers attend to share patient stories were suggested. Providing relevant, real experience was also documented by Meredith (2010) and is also recognised by the Australian Government via the creation and funding of the PCC4U project for health care curriculums. These education opportunities are essential given that providing palliative care content in university curriculum is related to positive outcomes for students, such as improved knowledge (Ballesteros et al., 2014, Kumar et al., 2011, Anderson et al., 2008) and personal development (Ballesteros et al., 2014), and is likely to result in less burnout and career fatigue (Breen et al., 2014). Speech pathologists will not benefit from a piecemeal approach; instead, palliative care content and experiences should be stipulated in the curriculum.

\section{Limitations and Future Research}

The current study has identified valuable information in relation to the Speech Pathologist's preparedness for work in palliative care and will pave the way for further research in this area to 
occur. Although several novel findings were documented, the study relied on Speech Pathologists commenting retrospectively on their preparedness and what they believed to have been taught in the curriculum. Given they were commenting retrospectively, they may not have accurately remembered the content they did or did not receive. Although Speech Pathologists were sampled from across Australia, the extent to which the sample, or the findings, is representative of all Speech Pathologists working in palliative care in Australia is unknown.

Continuation of this research will improve comprehensive, client-centred management and quality of life for palliative care patients. It is suggested that further research be conducted with coordinators of the Speech Pathology university curriculum, in order to determine what content is currently taught at the tertiary level in relation to palliative care. Once further information is obtained, it would be ideal to coordinate focus groups to identify teaching resources that would be beneficial, and to then determine if these resources improve preparedness of Speech Pathology graduates. Embedding more Speech Pathology specific content in the PCC4U program, may be a sufficient resource for student learning. Comparing the preparedness of students who complete a placement in palliative care, as opposed to those that only receive lecture material, would also be beneficial. Investigating the professional development opportunities that would be relevant for qualified Speech Pathologists, and how these can be provided at a community level, would also be valuable. Given this research was conducted with Australian-trained Speech Pathologists, it would be useful to conduct this research in other countries, in order to determine if Speech Pathology graduates elsewhere are better prepared for palliative care, and if so, to examine the differences across curriculums and professional development opportunities.

Palliative care patients are a complex area of Speech Pathology work. However, given the wide and varied range of Speech Pathology practice, future research could also investigate the preparedness of Speech Pathologists working in other contexts, for example head and neck cancer, traumatic brain injury, or children with cognitive impairments.

\section{Conclusions}


Palliative care education is currently not a core component of Speech Pathology university education or part of routine post-university training, even for those Speech Pathologists who work in palliative care. Increasing the access to, and uptake of, palliative care education available to Speech Pathologists would be invaluable to their ability to offer communication and swallowing support, and consultation to others in the palliative care team, all of which add value to palliative care service delivery. 


\section{References}

ANDERSON, W., WILLIAMS, J., BOST, J. \& BARNARD, D. 2008. Exposure to death is associated with positive attitudes and higher knowledge about end-of-life care in graduating medical students. Journal of Palliative Medicine, 11, 1227-1233.

AUSTRALIAN COMMISSION ON SAFETY AND QUALITY IN HEALTH CARE 2015. National Consensus Statement: Essential elements for safe and high-quality end-of-life care. Sydney, Australia: ACSQHC.

AUSTRALIAN INSTITUTE OF HEALTH AND WELFARE 2016. Australia's health 2016. Australia's health series no.15. Canberra: Australian Institute of Health and Welfare.

BALLESTEROS, M., CENTENO, C. \& ARANTZAMENDI, M. 2014. A qualitative exploratory study of nursing students' assessment of the contribution of palliative care learning. Nurse Education Today.

BREEN, L. J., O'CONNOR, M., HEWITT, L. Y. \& LOBB, E. A. 2014. The 'specter' of cancer: Exploring secondary trauma for health professionals providing cancer support and counseling. Psychological Services, 11, 60-67.

BUCHANAN, A., COOPER, I., FIELDING, A., FREEGARD, H., GODWIN, S., HIRD, K., ISTED, L., MIGLIORNO, P., MORTLEY, E., RUSSELL, M., SCHAPER, L. \& SOULOS, T. 2012. End of life. In: FReEGARD, H. \& ISTED, L. (eds.) Ethical Practice for Health Professionals. Second ed. Melbourne, Victoria: Cengage Learning.

BUSH, T. \& SHAHWAN-AKL, L. 2013. Palliative care education- does it influence future practice? Contemporary Nurse, 43, 172-177.

COHEN, J. 1988. Statistical power analysis for the behavioural sciences, Hillsdale, NJ, Lawrence Earlbaum Associates.

CRAWFORD, G. B. \& PRICE, S. D. 2003. Team working: palliative care as a model of interdisciplinary practice. Medical Journal of Australia, 179, 32-34. 
ECKMAN, S. \& ROE, J. 2005. Speech and language therapists in palliative care: what do we have to offer? International Journal of Palliative Nursing, 11, 179-181.

EMDEN, C. \& SANDELOWSKI, M. 1998. The good, the bad and the relative, part one: Conceptions of goodness in qualitative research. International Journal of Nursing Practice, 4, 206-212.

FROST, M. 2001. The role of physical, occupational and speech therapy in hospice: Patient empowerment. American Journal of Hospice and Palliative Medicine, 18, 397-402.

HAWKSLEY, R., LUDLOW, F., BUTTIMER, H. \& BLOCH, S, in press. Communication disorders in palliative care: investigating the views, attitudes and beliefs of speech \& language therapists. International Journal of Palliative Nursing.

HARPER, B. 1997. Growth in caring and professional ethics in Hospice. The HospiceJournal, 12, 65-70.

HSIEH, H. \& SHANNON, S. E. 2005. Three approaches to qualitative content analysis. Qualitative Health Research, 15, 1277-1288.

KUMAR, S., JIM, A. \& SISODIA, V. 2011. Effects of palliative care training program on knowledge, attitudes, beliefs and experiences among student physiotherapists: A preliminary quasiexperimental study. Indian Journal of Palliative Care, 17, 47-53.

MATHISEN, B., YATES, P. \& CROFTS, P. 2010. Palliative care curriculum for speech-language pathology students. International Journal of Language and Communication Disorders, 46, 273-285.

MEIER, D. E., BACK, A. L. \& MORRISON, R. S. 2001. The inner life of physicians and care of the seriously ill. The Journal of the American Medical Association, 286, 3007-3014.

MEREDITH, P. 2010. Has undergraduate education prepared occupational therapy students for possible practice in palliative care? Australian Occupational Therapy Journal, 57, 224-232.

MORRIS, J. \& LEONARD, R. 2007. Physiotherapy students' experiences of palliative care placementspromoting interprofessional learning and patient-centred approaches. Journal of Interprofessional Care, 21, 569-571.

POLLENS, R. 2004. Role of the speech-language pathologist in palliative hospice care. Journal of Palliative Medicine, 7, 694-702. 
POLLENS, R. 2012. Integrating speech-language pathology services in palliative end-of-life care. Topics in Language Disorders, 32, 137-148.

POTTER, R., SCHNEIDERMAN, R. \& GIBSON, G. 1979. Understanding death, dying, and the critically ill: A concern for Speech-Language Pathologists. Journal of Communication Disorders, 12, 495502.

RIVERS, K. O., PERKINS, R. A. \& CARSON, C. P. 2009. Perceptions of speech-pathology and audiology students concerning death and dying: a preliminary study. International Journal of Language and Communication Disorders, 44, 98-111.

ROE, J. \& LESLIE, P. 2010. Beginning of the end?: Ending the therapeutic relationship in palliative care. International Journal of Speech-Language Pathology, 12, 304-308.

ROE, J., LESLIE, P. \& DRINNAN, M. 2007. Oropharyngeal dysphagia: the experience of patients with non-head and neck cancers receiving specialist palliative care. Palliative Medicine, 21, 567574.

TEED, R. \& KEATING, J. 2009. Palliative care education in Australian physiotherapy undergraduate curriculum [Online]. Australia. Available: http://www.caresearch.com.au/caresearch/Portals/4/Documents/Report\%20on\%20Physioth erapy\%20Palliative\%20Care\%20Curriculum .pdf [Accessed September 15th 2014].

TONER, M. \& SHADDEN, B. 2012. End of life: an overview. Topics in Language Disorders, 32, 111-118.

TRUFFELLI, D. C., BENSI, C. G., GARCIA, J. B., NARAHARA, J. L., ABRAO, M. N., DINIZ, R. W. \& DEL GIGLIO, A. 2008. Burnout in cancer professionals: A systematic review and meta-analysis. European Journal of Cancer Care, 17, 524-531. 